\title{
Epicardial Ablation With Cooled Tip Catheter Close to the Coronary Arteries is Effective and Safe in the Porcine Heart if the Ventricular Potential is Being Monitored in the Epicardium and Endocardium
}

\author{
Mitsuharu Kawamura, MD; Youichi Kobayashi, MD; Hiroyuki Ito, MD; \\ Tatsuya Onuki, MD; Fumito Miyoshi, MD; Taka-aki Matsuyama, MD; \\ Norikazu Watanabe, MD; Shunshou Ryu, MD; Taku Asano, MD; \\ Akira Miyata, MD; Kaoru Tanno, MD; Takashi Katagiri, MD
}

\begin{abstract}
Background Transthoracic epicardial ablation can be an alternative to conventional treatment for critical pathways of ventricular tachycardia located in the epicardium. However, the usefulness and safety of epicardial ablation close to the coronary arteries (CA) is not clear. The purpose of the present experimental animal study was to analyze the efficacy and safety of epicardial radiofrequency (RF) ablation close to the CA.

Methods and Results Of the left ventricle-epicardium ablated sites, 35 lesions ( 20 with cooling and 15 without cooling) were close to the CA (left anterior descending artery $\leq 15 \mathrm{~mm}$ ) and 33 lesions ( 23 with cooling and 10 without cooling) were further from the CA. For sites close to the CA, epicardial ablation was effective in $77 \%$ $(15 / 20)$ with cooling and in $40 \%$ (6/15) without cooling. There was a significant difference of effective ablation between with cooling and without cooling $(\mathrm{p}<0.05)$. For cooling, epicardial lesion size could be predicted by the change of endocardial ventricular potential using a basket catheter. No damage to major epicardial arteries was detected when the catheter tip was positioned $5 \mathrm{~mm}$ away from the CA.

Conclusions Close to the $\mathrm{CA}, \mathrm{RF}$ ablation with cooling is more effective than RF without cooling and is safe if the ablation sites are located $5 \mathrm{~mm}$ away from the major CA. (Circ J 2006; 70: 926-932)
\end{abstract}

Key Words: Cooled-tip catheter; Coronary arteries; Epicardium; Radiofrequency ablation; Ventricular tachycardia

$\mathbf{E}$ ndocardial catheter ablation is a popular treatment for various types of arrhythmias, but it has limitations, including the inability to access foci or critical circuits of arrhythmia located in the epicardium. Technological improvements, such as cooled-tip or largertip ablation catheters and different energy sources for tissue ablation, have not completely solved this problem. Mapping of the arrhythmic foci or circuits in the epicardium has been done in open-chest heart surgery ${ }^{1}$ and with radiofrequency (RF) ablation catheters in 2 ways. First, a $2 \mathrm{~F}$ electrode catheter is inserted into the coronary sinus and then into the branches. Epicardial circuits can sometimes be identified with this approach, but only when the veins are near the circuit or foci? There is a possibility of damage to coronary arteries (CA) if the coronary sinus runs parallel to the CA, even if the circuit or foci are near the coronary sinus. Second, transthoracic epicardial ablation of ventricular tachycardia (VT) has recently been shown to be feasible,

(Received February 21, 2006; revised manuscript received April 4, 2006; accepted April 18, 2006)

Third Department of Internal Medicine, Showa University School of Medicine, Tokyo, Japan

Mailing address: Mitsuharu Kawamura, MD, The Third Department of Internal Medicine, Showa University School of Medicine, 1-5-8 Hatanodai, Shinagawa-ku, Tokyo 142-8666, Japan. E-mail: mitsu-0709 @ fiberbit.net primarily in patients with Chagas heart disease, ${ }^{3-5}$ ischemic cardiomyopathy, ${ }^{6-8}$ and dilated cardiomyopathy,, 10 However, the acute success rate of epicardial catheter ablation for VT using a standard RF catheter is only about $60 \%$, because the catheter electrode is inadequately cooled by the blood and the effect of epicardial fat in the vicinity of the CA. The lack of convective cooling of the catheter-tip by the blood would be expected to limit power delivery in the pericardial space; hence, the use of cooled-tip catheter ablation might be more appropriate than conventional catheter ablation for larger and deeper epicardial lesions. Furthermore, the safety of cooled-tip catheter ablation in the vicinity of the CA is unclear. The aim of the present study was to use an animal model to characterize the size of lesions produced by ablation with a cooled-tip catheter and to establish the safety of delivering RF pulses in the vicinity of major coronary vessels.

\section{Methods}

The current study was done according to the Guidelines for the Care and Use of Laboratory Animals published by the US National Institute of Health. The study protocol was reviewed by the Committee of the Ethics on Animal Experiments of Showa University. 
AP

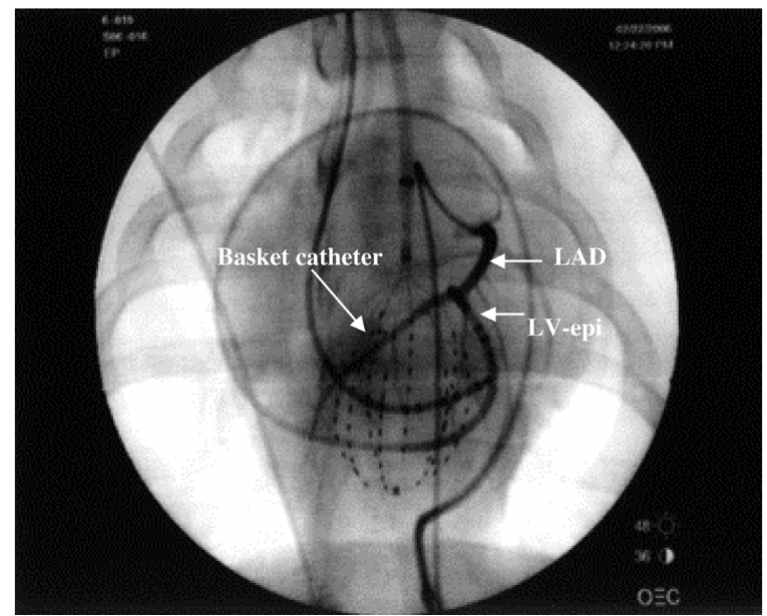

Fig 1. Radioscopic antero-posterior (AP) view showing a cooled tip catheter in the pericardial space and basket catheter in the left ventricular endocardium. Coronary angiography was done to assess the anatomic relationships between the ablation catheter and the coronary arteries (CA). LAD, left anterior descending artery; LV-epi, left ventricle-epicardium.

\section{Preparation of the Animals and Anatomic Approaches}

Fourteen healthy pigs, weighing $29-40 \mathrm{~kg}$ were used. Anesthesia was induced with $5 \mathrm{mg} / \mathrm{kg}$ of xylazine and $5 \mathrm{mg} / \mathrm{kg}$ of ketamine intravenously, and maintained with inhaled $1.1 \%-2.7 \%$ isoflurane. Pigs were intubated and ventilated with $\mathrm{N}_{2} \mathrm{O}$ and $\mathrm{O}_{2}(1: 1)$. The quadripolar diagnostic catheters were inserted through both femoral veins and positioned under fluoroscopic guidance in the His-bundle region and the right ventricular apex. Left ventricular endocardium (LV-endo) mapping was done using a basket catheter (Boston Scientific-EP Technologies), which was introduced through the right carotid artery. The basket catheter was 64 electrodes mounted on 8 flexible nitinol splines ( 8 ring electrodes per spline). Each spline was identified by a letter $(\mathrm{A}-\mathrm{H})$ and each electrode by a number, 1 being the most distal and 8 the most proximal. Basket catheter size was $38 \mathrm{~mm}$.

\section{Pericardial Approach}

The technique of pericardial approach was the same as previously described. An epidural needle (17G) was used for the pericardial puncture. The needle was advanced into the pericardial space under the guidance of fluoroscopy, and then a small bolus of contrast media was injected, and this was confirmed by diffusion of contrast media throughout the pericardial space. A guidewire was then passed through the needle, over which the $8 \mathrm{~F}$ sheath was advanced. After pouring saline $(50-100 \mathrm{ml})$ into the LVepicardium (LV-epi), a cooled-tip catheter (Chilli ablation catheter; Boston Scientific-EP Technologies) was passed through the sheath and advanced into the LV-epi.

\section{Ablation Protocol}

The cooled-tip catheter (closed type) was a $120 \mathrm{~cm}, 7 \mathrm{~F}$, deflectable, quadripolar catheter with an interelectrode distance of 2-5-2 $\mathrm{mm}$ and a $4 \mathrm{~mm}$ tip distal ablating electrode containing a thermocouple. RF ablation was done with cooling, during saline circulation at $0.6 \mathrm{ml} / \mathrm{m}$, with RF power set at $30 \mathrm{~W}$ for $60 \mathrm{~s}$. RF ablation was done without
Table 1 Rate of Effective Ablated Lesion With or Without Cooling

\begin{tabular}{lccc}
\hline \hline & With cooling & Without cooling & $p$ value \\
\hline LV-epi & $36 / 43(83 \%)$ & $14 / 25(56 \%)$ & $<0.05$ \\
Close to CA & $15 / 20(77 \%)$ & $6 / 15(40 \%)$ & $<0.05$ \\
Further from CA & $21 / 23(88 \%)$ & $8 / 10(80 \%)$ & $N S$ \\
LV-endo & $11 / 12(91 \%)$ & $8 / 10(80 \%)$ & $N S$ \\
\hline
\end{tabular}

LV-epi, left ventricle-epicardium; CA, coronary artery; LV-endo, left ventricle-endocardium.

cooling at a temperature of $60^{\circ} \mathrm{C}$ for $60 \mathrm{~s}$. Ablation was done for $60 \mathrm{~s}$, unless catheter dislodgement, impedance rise, or VT occurred sooner. Before RF ablation, coronary angiography was done to assess the anatomic relationships between the ablation catheter and the CA (Fig 1).

\section{Ventricular Potentials and Ablation of Lesions}

The amplitudes of ventricular potentials recorded at the ablation catheter and basket catheter were measured before and after application of RF energy to analyze the relationship between lesion volume and ventricular potential. The proportion by which ventricular potential decreased was calculated as follows: 100-(post-ventricular potential/preventricular potential $\times 100$ ).

\section{Pathological Examination}

One hour after RF ablation, the pigs were killed, and each heart was excised. Lesions on the epicardial surface were measured to quantify length along the long axis and short axis, and depth. Sections from grossly detectable lesions were fixed in $10 \%$ formalin. Tissue samples were dehydrated, embedded in paraffin, sectioned at $10 \mu \mathrm{m}$ thickness, and stained with hematoxylin and eosin and Masson's trichrome. Effectiveness of RF ablation was defined as visibility of the ablated lesion in the epicardium. Lesion volume was calculated by the following formula: $\{4 / 3 \pi$ (length/2) (width/2) (depth) $\} / 2$.

\section{Statistical Analysis}

An unpaired Student t-test was done for comparison of ablated lesions close to and further from CA. To compare ventricular potentials before and after RF ablation, a paired t-test was used. Statistical analysis was calculated with SAS software (SAS Institute). Values are expressed as mean $\pm S D$, and differences were considered statistically significant at $\mathrm{p}<0.05$.

\section{Results}

Rate of Effective Ablated Lesion With or Without Cooling

As shown in Table 1, using RF ablation with cooling, 36 of 43 lesions (83\%) were created and using RF ablation without cooling, 14 of 25 lesions $(56 \%)$ were created in the LV-epi. In the LV-epi, ablation with cooling was effective significantly more often than ablation without cooling $(\mathrm{p}<0.05)$. Of the LV-epi sites, 35 lesions (20 with cooling and 15 without cooling) were close to the CA left anterior descending artery (LAD) $\leq 15 \mathrm{~mm}$ ) and 33 lesions ( 23 with cooling and 10 without cooling) were further from the CA. For sites close to the CA, epicardial ablation was effective in $77 \%(15 / 20)$ with cooling and in $40 \%(6 / 15)$ without cooling. There was a significant difference between effective ablation using a cooled tip and that without cooling $(\mathrm{p}<0.05)$. For sites further from the CA, epicardial ablation 
Table 2 Characteristics of Epicardial Ablation (Close to Coronary Arteries vs Further From Coronary Arteries)

\begin{tabular}{|c|c|c|c|c|c|c|}
\hline & \multicolumn{6}{|c|}{$L V$-epi } \\
\hline & \multicolumn{3}{|c|}{ With cooling } & \multicolumn{3}{|c|}{ Without cooling } \\
\hline & $\begin{array}{c}\text { Close to } C A \\
\quad n=15\end{array}$ & $\begin{array}{c}\text { Further from } C A \\
\quad n=21\end{array}$ & $p$ value & $\begin{array}{c}\text { Close to } C A \\
n=6\end{array}$ & $\begin{array}{c}\text { Further from } C A \\
n=8\end{array}$ & $p$ value \\
\hline Temperature $\left({ }^{\circ} \mathrm{C}\right)$ & $31.3 \pm 6.2$ & $33.3 \pm 7.6$ & NS & $56.2 \pm 13$ & $58.1 \pm 11$ & NS \\
\hline Power $(W)$ & $29.3 \pm 15$ & $27.3 \pm 12$ & NS & $13.6 \pm 3$ & $11.1 \pm 4$ & $N S$ \\
\hline Impedance $(\Omega)$ & $136 \pm 28$ & $138 \pm 34$ & $N S$ & $129 \pm 29$ & $139 \pm 44$ & $N S$ \\
\hline Energy $(J)$ & $1,127 \pm 187$ & $1,021 \pm 224$ & $N S$ & $853 \pm 111$ & $823 \pm 141$ & $N S$ \\
\hline$R F$ application time (s) & $56 \pm 21$ & $54 \pm 26$ & $N S$ & $54 \pm 30$ & $57 \pm 23$ & $N S$ \\
\hline Impedance rise & 2 & 1 & $N S$ & 3 & 2 & $N S$ \\
\hline Surface length (mm) & $9.2 \pm 2.3$ & $11.9 \pm 3.8$ & $N S$ & $5.7 \pm 1.9$ & $8.7 \pm 1.6$ & $<0.05$ \\
\hline Surface width (mm) & $8.4 \pm 2.1$ & $9.6 \pm 2.1$ & $N S$ & $4.7 \pm 1.0$ & $7.1 \pm 1.1$ & $<0.05$ \\
\hline Depth $(\mathrm{mm})$ & $4.4 \pm 1.6$ & $7.1 \pm 2.0$ & $<0.05$ & $1.8 \pm 0.3$ & $4.1 \pm 1.1$ & $<0.01$ \\
\hline $\begin{array}{l}\text { Ventricular potential } \\
\text { Pre- } R F(m V)\end{array}$ & $10.3 \pm 2.2$ & $16.3 \pm 4.6$ & $<0.05$ & $10.4 \pm 2.5$ & $16.8 \pm 3.9$ & $<0.05$ \\
\hline $\begin{array}{l}\text { Ventricular potential } \\
\text { Post-RF }(\mathrm{mV})\end{array}$ & $6.9 \pm 1.6$ & $9.7 \pm 1.9$ & $<0.05$ & $8.7 \pm 1.8$ & $11.9 \pm 4.2$ & $N S$ \\
\hline
\end{tabular}

$R F$, radiofrequency. Other abbreviations see in Table 1.

(A)

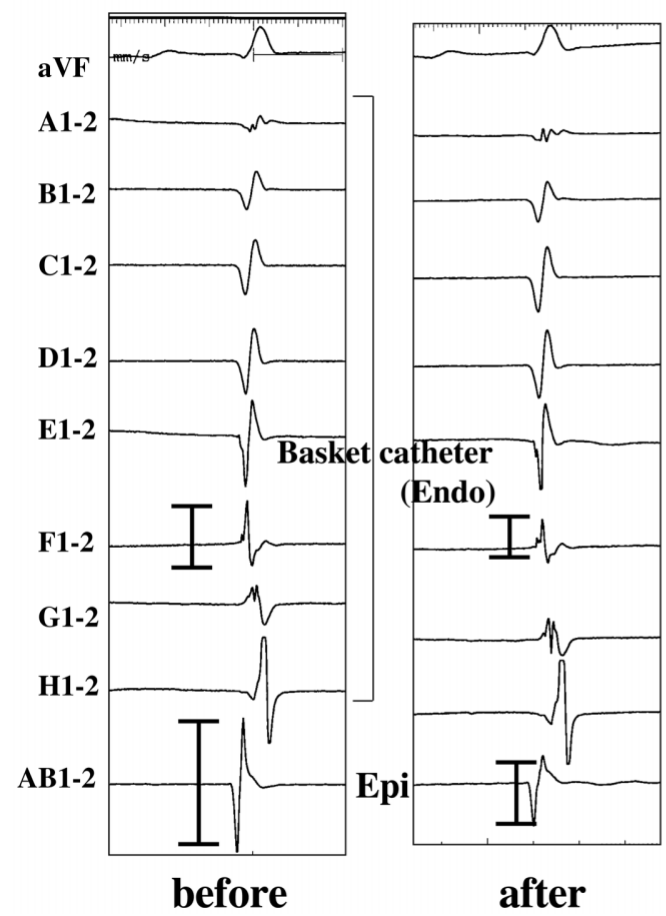

(B)

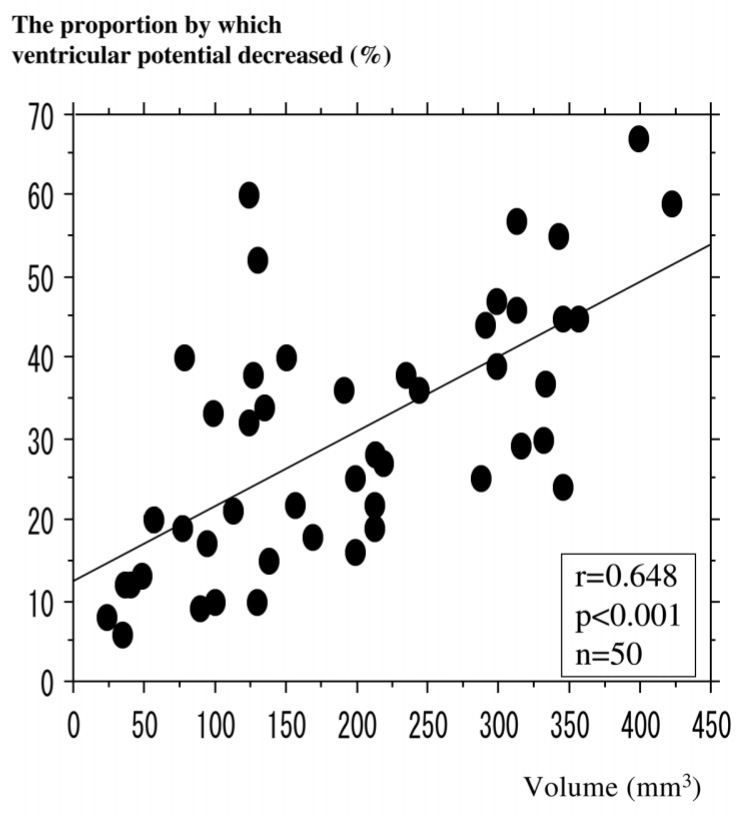

The proportion by which ventricular potential decreased $(\%)$

Fig 2. (A) The change of epicardial and endocardial ventricular potential (pre- and post-radiofrequency (RF) ablation). The amplitude of epicardial ventricular potential obtained from ablation catheter (AB 1-2) was decreased $16 \mathrm{mV}$ to $7 \mathrm{mV}$ after RF application. The amplitude of endocardial ventricular potential obtained from basket catheter (F1-2) was decreased $10 \mathrm{mV}$ to $6 \mathrm{mV}$ after RF application. (B) Relationship between the proportion by which ventricular potential decreased $(\%)$ and the volume $\left(\mathrm{mm}^{3}\right)$. Endo, endocardial; Epi, epicardium.

was effective in $88 \%(21 / 23)$ with cooling and in $80 \%$ $(8 / 10)$ without cooling. There was no significant difference between ablation with cooling and without cooling.

\section{Parameters of Ablation in the LV-epi (Sites Close to the CA} vs Those Further From the CA)

LV-epi Ablation With Cooling Characteristics of ablation are shown in Table2. Temperature and power did not differ significantly between ablations performed close to the $\mathrm{CA}$ and those done further from the CA. Initial impedances did not differ significantly between both groups either. Impedance rises were seen for 3 lesions ( 2 close to the CA and 1 further from the CA). Surface length and width did not differ significantly between the 2 groups. However, depth was significantly shallower for lesions close to the CA than for those further from the CA (4.4 \pm $1.6 \mathrm{~mm}$ vs $7.1 \pm 2.0 \mathrm{~mm}, \mathrm{p}<0.05$ ). Moreover, volume was significantly smaller for lesions close to the CA than for those further from the CA $\left(173 \pm 57 \mathrm{~mm}^{3}\right.$ vs $422 \pm 118 \mathrm{~mm}^{3}$, $\mathrm{p}<0.01)$.

LV-epi Ablation Without Cooling Temperature and power did not differ significantly between ablations per- 
formed close to the CA and those done further from the CA. Initial impedances did not differ significantly between both groups either. Impedance rises were seen for 5 lesions (3 close to the CA and 2 further from the CA). Surface length, width, and depth were significantly smaller in lesions close to the CA. Moreover, volume was significantly smaller for lesions close to the CA $\left(38 \pm 22 \mathrm{~mm}^{3}\right.$ vs $125 \pm 23 \mathrm{~mm}^{3}$, $\mathrm{p}<$ $0.01)$.

Comparison of Cooling-on RF Ablation and Cooling-off $R F$ Ablation For sites close to the CA, mean power was $29.3 \pm 15 \mathrm{~W}$ with cooling and $13.6 \pm 3 \mathrm{~W}$ without cooling $(\mathrm{p}<0.01)$. The lesion surface length, width, and depth were significantly larger when ablation with cooling was used. For sites further from the CA, mean power was significantly higher for ablation with cooling than for that without $(27.3 \pm 12 \mathrm{~W}$ vs $11.1 \pm 4 \mathrm{~W}, \mathrm{p}<0.01)$. The surface length and width did not differ significantly between the 2 types of ablation; however, depth was significantly greater using ablation with cooling. Furthermore, frequency of impedance rise was less ablation with cooling than that without cooling.

\section{Change of Epicardial Ventricular Potential}

As shown in Fig $2 \mathrm{~A}$, epicardial ventricular potential changed after RF ablation. The ventricular potential obtained from the ablation catheter (AB 1-2) decreased from $16 \mathrm{mV}$ to $7 \mathrm{mV}$ (53\%) after RF application. For sites close to the $\mathrm{CA}$, the proportion by which ventricular potential decreased was significantly higher using ablation with cooling than using that without cooling $(32 \pm 19 \%$ vs $12 \pm$ $10 \%, \mathrm{p}<0.01)$. For sites further from the CA, the proportion by which ventricular potential decreased did not differ significantly between with cooling and without cooling $(39 \pm 22 \%$ vs $28 \pm 19 \%)$. For ablation with cooling, the proportion by which ventricular potential decreased did not differ significantly between sites close to the CA and those further from the CA $(32 \pm 19 \%$ vs $39 \pm 22 \%)$. For ablation without cooling, the proportion by which ventricular potential decreased was significantly lower for sites close to the CA than those further from the CA $(12 \pm 10 \%$ vs $28 \pm 19 \%)$. As shown in Fig 2B, ablated lesion volume was significantly correlated with the proportion by which ventricular potential decreased $(\mathrm{r}=0.648 ; \mathrm{p}<0.0001)$.
Table 3 Endocardial Ventricular Potential Using Basket Catheter

\begin{tabular}{lcccc}
\hline \hline & \multicolumn{2}{c}{ With cooling } & & Without cooling \\
\cline { 2 - 3 } \cline { 5 - 5 } & $\begin{array}{c}\text { Change- } \\
\text { group }\end{array}$ & $\begin{array}{c}\text { No change- } \\
\text { group }\end{array}$ & & $\begin{array}{c}\text { No change- } \\
\text { group }\end{array}$ \\
\hline$N$ & 5 & 21 & & 6 \\
Depth $(\mathrm{mm})$ & $6.1 \pm 1.2$ & $3.4 \pm 0.9$ & & $2.2 \pm 0.6$ \\
Volume $\left(\mathrm{mm}^{3}\right)$ & $343 \pm 98$ & $156 \pm 63$ & & $89 \pm 23$ \\
Ventricular potential & $12.3 \pm 4.2$ & $10.5 \pm 2.0$ & & $10.9 \pm 2.5$ \\
$\quad$ Pre- $R F(\mathrm{mV})$ & & & & \\
Ventricular potential & $8.6 \pm 3.2$ & $0.2 \pm 1.8$ & & $10.0 \pm 1.5$ \\
$\quad$ Post- $R F(\mathrm{mV})$ & & & \\
\hline
\end{tabular}

Abbreviation see in Table 2.

\section{Change of Endocardial Ventricular Potentials (Basket Catheter)}

Using the basket catheter, we examined how endocardial ventricular potentials were influenced by epicardial ablation. As shown in Table 3, endocardial ventricular potentials decreased in 5 of 26 lesions created using ablation with cooling; all these sites were anterolateral. Furthermore, there were no lesions created using ablation without cooling $(0 / 6)$. Average lesion depth was significantly greater in the 5 lesions in which endocardial ventricular potential changed than in the 21 unchanged lesions $(6.1 \pm 1.2 \mathrm{~mm}$ vs $3.4 \pm$ $0.9 \mathrm{~mm}, \mathrm{p}<0.05)$. The average lesion volume was significantly greater in the 5 lesions in which endocardial ventricular potential changed than in the 21 unchanged lesions $\left(343 \pm 98 \mathrm{~mm}^{3}\right.$ vs $\left.156 \pm 63 \mathrm{~mm}^{3}, \mathrm{p}<0.01\right)$. Fig $2 \mathrm{~A}$ illustrates a typical example. In the $\mathrm{F}$ spline, the endocardial ventricular potential decreased from $10 \mathrm{mV}$ to $6 \mathrm{mV}(40 \%)$ after $\mathrm{RF}$ application.

\section{With Cooling and Without Cooling Epicardial Ablation Lesions}

As shown in Fig 3A, lesions created by RF ablation with cooling tended to be located near the LAD, whereas lesions created without cooling tended to be located further from the LAD, in areas covered with epicardial fat. After stripping the epicardial fat, lesions ablated without cooling did not reach the myocardium (Fig 3B). However, with cooling, lesions reached the myocardium and tended to be larger. As shown in Fig 4A, the 2 lesions created with cooling were located above the LAD (B area) and $5 \mathrm{~mm}$ away from the
(A)

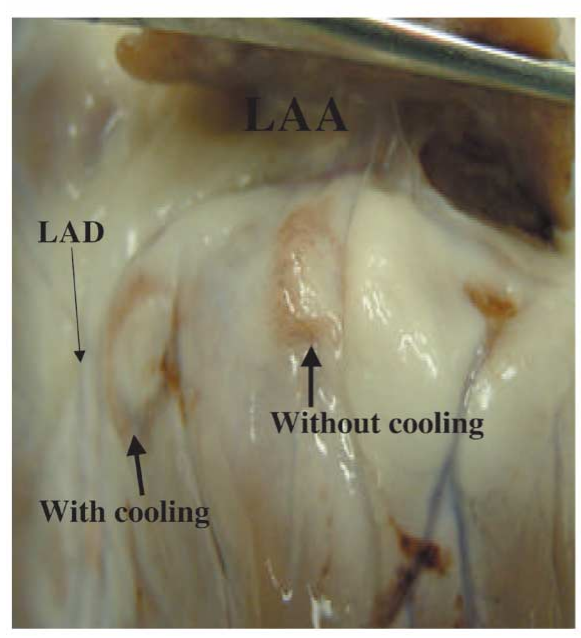

(B)

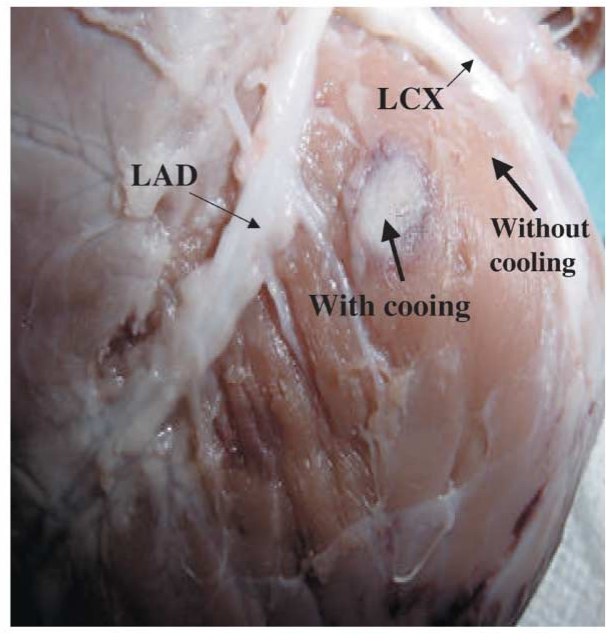

Fig 3. The gross view of the ablated lesions. (A) The ablated lesion by cooling-on radiofrequency (RF) ablation was located near the left anterior descending artery (LAD). The ablated lesion by cooling-off RF ablation was located in the further from the LAD (black arrow). These places were covered with the epicardial fat. (B) After the epicardial fat was striped, the ablated point by cooling-off RF ablation did not reach to the myocardium. LCX, left circumflex coronary artery. 


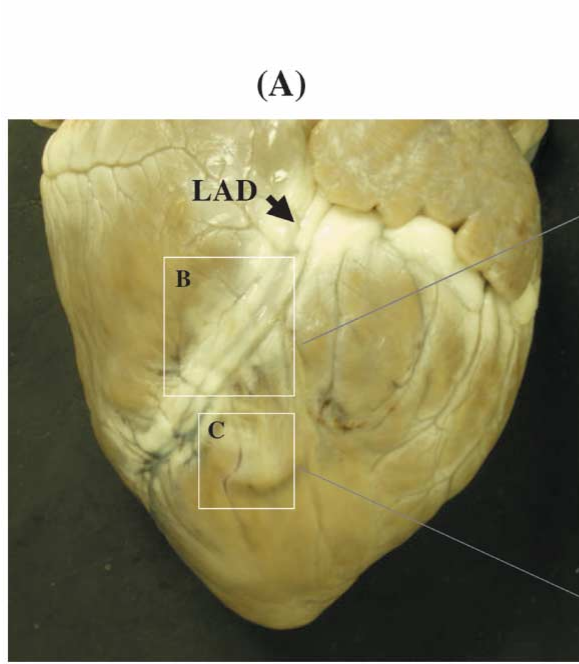

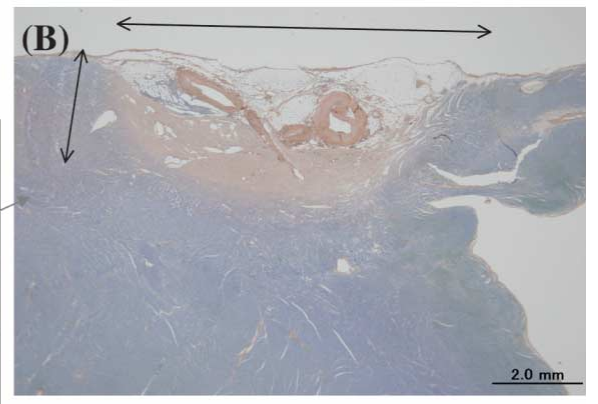

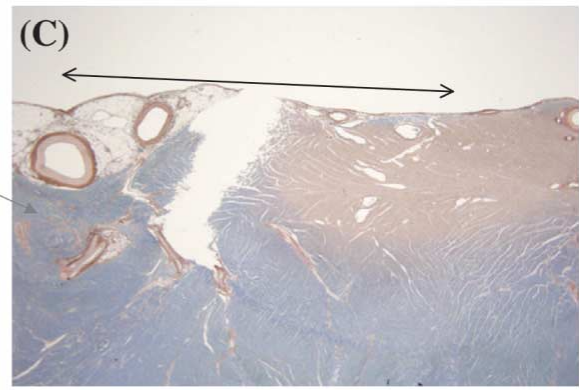

Fig 4. Cooling-on radiofrequency (RF) epicardial ablation lesions. (A) The ablated 2 lesions by cooling-on $\mathrm{RF}$ ablation were located above the left anterior descending artery (LAD) (B area) and $5 \mathrm{~mm}$ away from the LAD (C area) on gross anatomy. (B) Histopathological slides of epicardial lesions. The lesion size was $8.3 \mathrm{~mm}$ in length, $3.2 \mathrm{~mm}$ in depth. The epicardial fat was $0.45 \mathrm{~mm}$. The LAD was damaged. (C) The lesion size was $8.8 \mathrm{~mm}$ in length, $3.9 \mathrm{~mm}$ in depth. The catheter-tip was $5.3 \mathrm{~mm}$ away from the LAD. There was no damage of the coronary arteries.
LAD (C area) macroscopically. The B area lesion was $8.3 \mathrm{~mm}$ in length and $3.2 \mathrm{~mm}$ in depth. The epicardial fat was $0.45 \mathrm{~mm}$ in depth at this region (Fig 4B). The LAD was damaged in area B. In Fig 4C, the lesion was $8.8 \mathrm{~mm}$ in length and $3.9 \mathrm{~mm}$ in depth. The catheter tip was positioned $5.3 \mathrm{~mm}$ away from the LAD and no damage to CA was evident. In the present study, 7 ablated lesions were created above or within $5 \mathrm{~mm}$ of the LAD and 4 of these involved LAD injury. In the 4 applications involving LAD injury, average power was $29.4 \pm 11 \mathrm{~W}$ and the average epicardial fat was $0.43 \pm 0.05 \mathrm{~mm}$. In another 3 applications, average power was $27.6 \pm 9 \mathrm{~W}$ and the average epicardial fat was $0.47 \pm 0.08 \mathrm{~mm}$.

There was no significant difference between both groups however 4 applications involving LAD injury used greater power and less fat. Thirteen ablated lesions were created more than $5 \mathrm{~mm}$ away from the LAD and none of these involved coronary vessel damage.

\section{Discussion}

Sosa et al first reported transthoracic epicardial ablation in 1996? The method has since been adapted for use in ablating a variety of other arrhythmias including postmyocardial infarction VT, idiopathic VT, atrial fibrillation, and Wolf-Parkinson-White syndrome syndrome.1 Previous studies have investigated electrocardiogram characteristics of VT originating from the right ventricular outflow tract ${ }^{12}$ and the LV-epi $1^{13-15}$ However, the safety and efficacy of epicardial RF ablation especially in the vicinity of the CA remain unclear. The present study showed that: (1) epicardial RF ablated lesions close to the CA were shallower and smaller than those further from the CA; (2) for sites close to the $\mathrm{CA}$, ablation with cooling produced larger and deeper lesions than that without cooling; (3) the ablated lesion volume was strongly correlated with the proportion by which ventricular potential decreased after ablation; (4) for cooling, epicardial lesion size could be assessed by the change of endocardial ventricular potential using a basket catheter; and (5) no damage to major epicardial arteries occurred when the catheter tip was positioned $5 \mathrm{~mm}$ away from these arteries.

\section{Epicardial Ablation}

Ablation with cooling has been shown to allow production of larger lesions in animal models ${ }^{16-22}$ and humans, ${ }^{23}$ presumably by allowing greater energy delivery before coagulation formation. This potential for larger lesion size is expected to increase the likelihood of successful ablation. However, in these studies, ablation was delivered only to the endocardium. Few reports have examined the use of RF ablation with cooling in the pericardial space, reporting that the cooled-tip catheter allowed the creation of deeper lesions and that active cooling of the ablation-tip help prevent the formation of coagulum and elevations of impedance. The present study had similar findings. In the epicardial space, the initial impedance was higher than that of the endocardium; probably because this region has no blood flow, catheter electrode-tissue contact was poor, and myocardial tissue is covered by epicardial fat near the major epicardial arteries. In the LV-epi, impedance rose easily in $\mathrm{RF}$ ablation without cooling because of the absence of convective cooling of the catheter-tip by the blood flow.

\section{Ventricular Potential}

D'Avila et al reported that the magnitude of the impedance drop correlated best with lesion dimension and that lesion depth was best predicted by a combination of impedance drop and power? 25 However, impedance drop and volume were not correlated in the present study $(r=0.229$, $\mathrm{p}=0.11$ ); hence, impedance drop was not an ablation index for epicardial ablation. Instead, we found that the proportion by which ventricular potential decreased was best correlated with lesion volume. This relationship was seen in the endocardium as well as in the epicardium. The relationship has not previously been documented; the proportion by which ventricular potential decreased might therefore represent a new ablation index in epicardial ablation. It is clear that epicardial lesion size could be predicted by the change of endocardial ventricular potential using a basket catheter. Both this proportion and initial ventricular potential were lower in the LV-epi than in the LV-endo; 
this might be explained by the fact that epicardial fat interposed between the catheter-tip and myocardial tissue, resulting in poor catheter tip-tissue contact ${ }^{24,25}$

\section{Close to the CA vs Further From the CA}

Robert et al reported successful ablations were done in the vicinity of major epicardial vessels. However, their study did not include ablation sites on or immediately adjacent to the $\mathrm{CA}^{26}$ Recent animal data have shown that ablated lesions created over epicardial vessels produce significant damage only to the smallest epicardial CA; CA injury did not occur when ablations were delivered parallel and $1 \mathrm{~cm}$ away from these vessels ${ }^{11}$ In the current study, when RF applications were delivered directly above the CA, coronary vessels were damaged. This might be because the media was directly damaged by ablation or because it was made more fragile by ablation and was then damaged during tissue sectioning despite of greater blood flow of the CA. However, when the catheter tip was positioned $5 \mathrm{~mm}$ away from the CA, the coronary vessels were not damaged, possibly because the epicardium, particularly that around the LAD, was covered with fat ${ }^{26}$ Ablated lesions close to the CA were accordingly smaller than those further from the CA. Close to the CA, we consider that epicardial RF ablation without cooling is likely to be ineffective. In these areas, ablation with cooling monitoring endocardial potential appears to be a better method and does not cause damage to major epicardial arteries when the catheter tip is positioned $5 \mathrm{~mm}$ away from the arteries.

\section{Complications}

During the approach to the epicardial space, ventricular perforation occurred in 2 pigs and hematoma of the epicardial space also occurred in 2 pigs. However, these complications occurred in the early stages of the current study, before we became accustomed to the technique of approaching the epicardial space. During epicardial RF ablation, 3 pigs developed ventricular fibrillation. Lung damage did not occur in the present study; this complication is dependent on the contact and orientation of the catheter relative to the lung tissue.

\section{Clinical Implications}

1) These findings of the present study show that the endocardium can be influenced by RF ablation with cooling from the epicardium; this technique is applicable for VT circuits that incorporate the myocardium. 2) RF ablation with cooling is safe in the short term if ablation sites are $5 \mathrm{~mm}$ away from the major CA or ventricular potentials are monitoring during ablation. Hence, it might be possible to expand the areas potentially suited for ablation to include regions close to the $\mathrm{CA}$.

\section{Study Limitations}

In the present study, complications were only assessed in the short term; long term complications are unclear and can include stenosis caused by inflammation of CA and adhesions of the epicardium. RF ablation with cooling produced significantly deeper lesions than that without cooling. We only did ablation in the $\mathrm{LV}$, and did not examine the right ventricle. As the right ventricle wall is thinner, cardiac perforation is more likely here due to cooled-tip RF ablation. Further studies are necessary to assess safety of such techniques in the right ventricle.

\section{Conclusions}

Ablation with cooling is safe in the short term if ablation sites are located $5 \mathrm{~mm}$ away from the major CA. Furthermore, the epicardial ablated lesion size could be assessed by the change of endocardial ventricular potentials using basket catheter.

\section{References}

1. Svenson RH, Littmann L, Gallagher JJ, Selle JG, Zimmern SH, Fedor JM, et al. Termination of ventricular tachycardia with epicardial laser photocoagulation: A clinical comparison with patients undergoing successful endocardial photocoagulation alone. J Am Coll Cardiol 1990; 15: 163-170.

2. Stellbrink C, Diem B, Schauerte P, Ziegert K, Hanrath P. Transcoronary venous radiofrequency catheter ablation of ventricular tachycardia. J Cardiovasc Electrophysiol 1997; 8: 916-921.

3. Sosa E, Scanavacca M, D’Avila A, Bellotti G, Pilleggi F. Radiofrequency catheter ablation of ventricular tachycardia guided by nonsurgical epicardial mapping in chronic Chagasic heart disease. Pacing Clin Electrophysiol 1999; 22: 128-130.

4. Sosa E, Scanavacca M, D’Avila A, Piccioni J, Sanchez O, Velarde JL, et al. Endocardial and epicardial ablation guided by nonsurgical transthoracic epicardial mapping to treat recurrent ventricular tachycardia. J Cardiovasc Electrophysiol 1998; 9: 229-239.

5. Sosa E, Scanavacca M, D’Avila A, Pilleggi F. A new technique to perform epicardial mapping in the electrophysiology laboratory. $J$ Cardiovasc Electrophysiol 1996; 7: 531-536.

6. Sosa E, Scanavacca M, D'Avila A, Oliveria F, Ramires JA. Nonsurgical transthoracic epicardial catheter ablation to treat recurrent ventricular tachycardia occurring late after myocardial infarction. J Am Coll Cardiol 2000; 35: 1442-1449.

7. Tomassoni G, Stanton M, Richey M, Leonelli FM, Beheiry S, Natale A. Epicardial mapping and radiofrequency catheter ablation of ischemic ventricular tachycardia using three-dimensional nonfluoroscopic mapping system. J Cardiovasc Electrophysiol 1999; 10: $1643-1648$.

8. Brugada J, Berruezo A, Cuesta A, Osca J, Chueca E, Fosch X, et al. Nonsurgical transthoracic epicardial radiofrequency ablation: An alternative in incessant ventricular tachycardia. J Am Coll Cardiol 2003; 41: 2036-2043.

9. Swarup V, Morton JB, Arruda M, Wilber DJ. Ablation of epicardial macroreentrant ventricular tachycardia associated with idiopathic nonischemic dilated cardiomyopathy by a percutaneous transthoracic approach. J Cardiovasc Electrophysiol 2002; 13: 1164-1168.

10. Tada H, Ito S, Naito S, Kurosaki K, Ueda M, Shinbo G, et al. Prevalence and electrocardiographic characteristics of idiopathic ventricular arrhythmia originating in the free wall of the right ventricular outflow tract. Circ J 2004; 68: 909-914.

11. D'Avila A, Gutierrez P, Scanavacca M, Reddy V, Lustgarten DL, Sosa E, et al. Effects of radiofrequency pulses delivered in the vicinity of the coronary arteries: Implications for nonsurgical transthoracic epicardial catheter ablation to treat ventricular tachycardia. Pacing Clin Electrophysiol 2002; 25: 1488-1495.

12. Soejima K, Stevenson WG, Sapp JL, Selwyn AP, Couper G, Epstein LM. Endocardial and epicardial radiofrequency ablation of ventricular tachycardia associated with dilated cardiomyopathy: The importance of low-voltage scars. J Am Coll Cardiol 2004; 43: 1834-1842.

13. Tada H, Nogami A, Naito S, Fukuzawa H, Horie Y, Kubota S, et al. Left ventricular epicardial outflow tract tachycardia: A new distinct subgroup of outflow tract tachycardia. Jpn Circ J 2001; 65: 723 730 .

14. Berruezo A, Mont L, Nava S, Chueca E, Bartholomay E, Brugada J. Electrocardiographic recognition of the epicardial origin of ventricular tachycardias. Circulation 2004; 109: 1842-1847.

15. Tanner H, Hindricks G, Schirdewahn P, Kobza R, Dorszewski A, Piorkowski C, et al. Outflow tract tachycardia with R/S transition in lead V3. J Am Coll Cardiol 2005; 45: 418-423.

16. Ruffy R, Imran MA, Santel DJ, Wharton JM. Radiofrequency delivery through a cooled catheter tip allows the creation of larger endomyocardial lesions in the ovine heart. $J$ Cardiovasc Electrophysiol 1995; 6: 1089-1096.

17. Nakagawa H, Yamanashi WS, Pitha JV, Arruda M, Wang X, Ohtomo $\mathrm{K}$, et al. Comparison of in vivo tissue temperature profile and lesion geometry for radiofrequency ablation with a saline-irrigated electrode versus temperature control in a canine thigh muscle preparation. Circulation 1995; 91: 2264-2273. 
18. Nakagawa H, Wittkampf FH, Yamanashi WS, Pitha JV, Imai S, Campbell B, et al. Inverse relationship between electrode size and lesion size during radiofrequency ablation with active electrode cooling. Circulation 1998; 98: 458-465.

19. Watanabe I, Masaki R, Min N, Oshikawa N, Okubo K, Sugimura H, et al. Cooled-tip ablation results in increased radiofrequency power delivery and lesion size in the canine heart: Importance of cathetertip temperature monitoring for prevention of popping and impedance rise. J Interv Card Electrophysiol 2002; 6: 9-16.

20. Reddy VY, Neuzil P, Taborsky M, Ruskin JN. Short-term results of substrate mapping and radiofrequency ablation of ischemic ventricular tachycardia using a saline-irrigated catheter. J Am Coll Cardiol 2003; 41: 2228-2236.

21. Delacretaz E, Stevenson WG, Winters GL, Mitchell RN, Stewart S, Lynch K, et al. Ablation of ventricular tachycardia with a salinecooled radiofrequency catheter: Anatomic and histologic characteristics of the lesions in humans. J Cardiovasc Electrophysiol 1999; 10: $860-865$.

22. Blaufox AD, Numan MT, Laohakunakorn P, Knick B, Paul T, Saul JP. Catheter tip cooling during radiofrequency ablation of intra-atrial reentry: Effects on power, temperature, and impedance. $J$ Cardiovasc Electrophysiol 2002; 13: 783-787.

23. Okishige K, Aonuma K, Yamauchi Y, Azegami K, Suzuki K, Isobe $\mathrm{M}$, et al. Clinical study of efficacy of a cooled-tip catheter ablation system for common atrial flutter. Circ $J$ 2004; 68: 73-76.

24. D’Avila A, Houghtaling C, Gutierrez P, Vragovic O, Ruskin JN, Josephson ME, et al. Catheter ablation of ventricular epicardial tissue: A comparison of standard and cooled-tip radiofrequency energy. Circulation 2004; 109: 2363-2369.

25. Reddy VY, Wrobleski D, Houghtaling C, Josephson ME, Ruskin JN. Combined epicardial and endocardial electroanatomic-mapping in a porcine model of healed myocardial infarction. Circulation 2003; 107: $3236-3242$.

26. Schweikert RA, Saliba WI, Tomassoni G, Marrouche NF, Cole CR, Dresing TJ, et al. Percutaneous pericardial instrumentation for endoepicardial mapping of previously failed ablations. Circulation 2003; 108: $1329-1335$.

27. D’Avila A, Scanavacca M, Sosa E, Ruskin JN, Reddy VY. Pericardial anatomy for the interventional electrophysiologist. J Cardiovasc Electrophysiol 2003; 14: 422-430. 